ORIGINAL ARTICLE

\title{
Understanding Patient's Predisposition for Physician's apparel: A Cross-sectional Study from Mayo Hospital, Lahore.
}

\author{
MUHAMMAD FAREED KHALID ${ }^{1}$, MAHBOOB ALAM², FAKEHA REHMAN ${ }^{3}$, RAHAT SARFARAZ ${ }^{4}$ \\ ${ }_{1,2}$ House Officers, Mayo Hospital, Lahore \\ ${ }^{3}$ Associate Professor of Pathology, King Edward Medical, University, Lahore. \\ ${ }^{4}$ Professor of Pathology, King Edward Medical University, Lahore \\ Corresponding author: Dr. Muhammad Fareed Khalid, Email: mfareedkhalidmfk@gmail.com, Contact: 03233815422
}

\begin{abstract}
Objective: To understand patient's predisposition for physician's apparel

Methodology: Using a cross-sectional study design, a total of 96 participants were approached at Mayo Hospital, Lahore. An interview based pre-tested semi structured questionnaire consisting of both open and close ended questions was used for data collection. Data was analyzed using SPSS version 26

Results: Out of 96 patients, $48(50 \%)$ were male and $48(50 \%)$ were female. Out of these $78.1 \%$ believed that doctor's dress is important to them. $63.5 \%$ of patients preferred name tag and $84.4 \%$ preferred whitecoat. The most desired apparel for male physician was western attire with white coat $(53.1 \%)$ and national attire with white coat for female doctors $(54.2 \%)$

Conclusion: This study accentuated the patients' predisposition for physician's apparel which can lead to better rapport and ultimately improved healthcare services.

Keywords: physician apparel, patient preference, attire
\end{abstract}

\section{INTRODUCTION}

Since the inception of medical profession, a physician's apparel has been considered to be an emblem of esteem and proficiency ${ }^{[1]}$, dating back to Hippocrates ${ }^{[2]}$. As per a study, it was established that patients felt more inclined to open about their issues to physicians who are professionally dressed [3]. Therefore, the white coat cemented itself as an elemental part of medical profession during the $20^{\text {th }}$ century. It has become evident that white coat helped creating a more conducive environment for doctor-patient relationship and patients perceived such doctors to be more distinguishable, sanitary and professional ${ }^{[4,5]}$. It has been documented that patients prefer their doctors to wear name tags ${ }^{[6,7,8]}$.

This predilection differ according to age [9], geographical location [10] and clinical setting ${ }^{[11]}$. A very minimal data is available in Pakistan regarding the predisposition of patients for how the doctors dress. A study carried out in Islamabad found out that patients prefer decent and professional attire along with white coat [12]

The aim of their study is to determine whether patients are of view that the doctor's attire plays a significant role in doctor-patient interaction and, if so, what would they regard as the best garb for the optimal interface.

\section{METHODOLOGY}

A cross sectional study was done from November 2020 to January 2021 in Mayo Hospital, Lahore which is a tertiary care hospital for providing medical facilities to ailing people of lower socioeconomic class hailing from Lahore and its surrounding localities. A total of 96 patients were included in the study as calculated by using a confidence level of $95 \%$, absolute precision as $10 \%$ and estimated response on doctor's attire as $46 \%{ }^{[12]}$. Patients of 18 years or older were approached in medical, surgical, and emergency specialties. They were requested to fill a questionnaire. It included questions both in Urdu and English language. It consisted of two sections. First section comprised of biodata, second section was divided into part $A$ and $B$. For part $A$, a total of twelve photographs were shown to the patient. Six were of female doctor and six were of male doctor (Fig.1). Then the patient was asked to rank those photos in order of his preference on the Likert scale ranging from strongly disagree to strongly agree.

Part B consisted of both open and close ended question. The data was then analyzed using SPSS and the results were presented in form of tables and graphs.

Received on 12-02-2021

Accepted on 09-06-2021
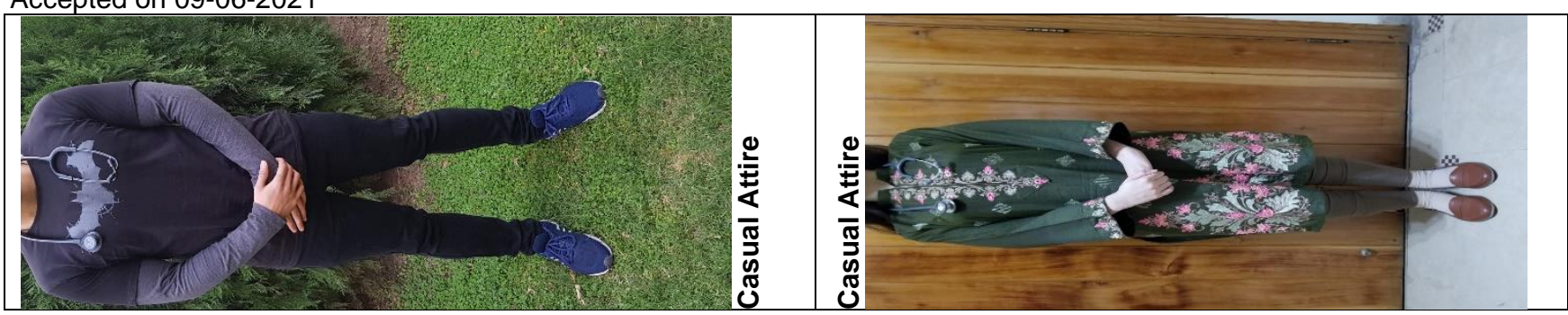

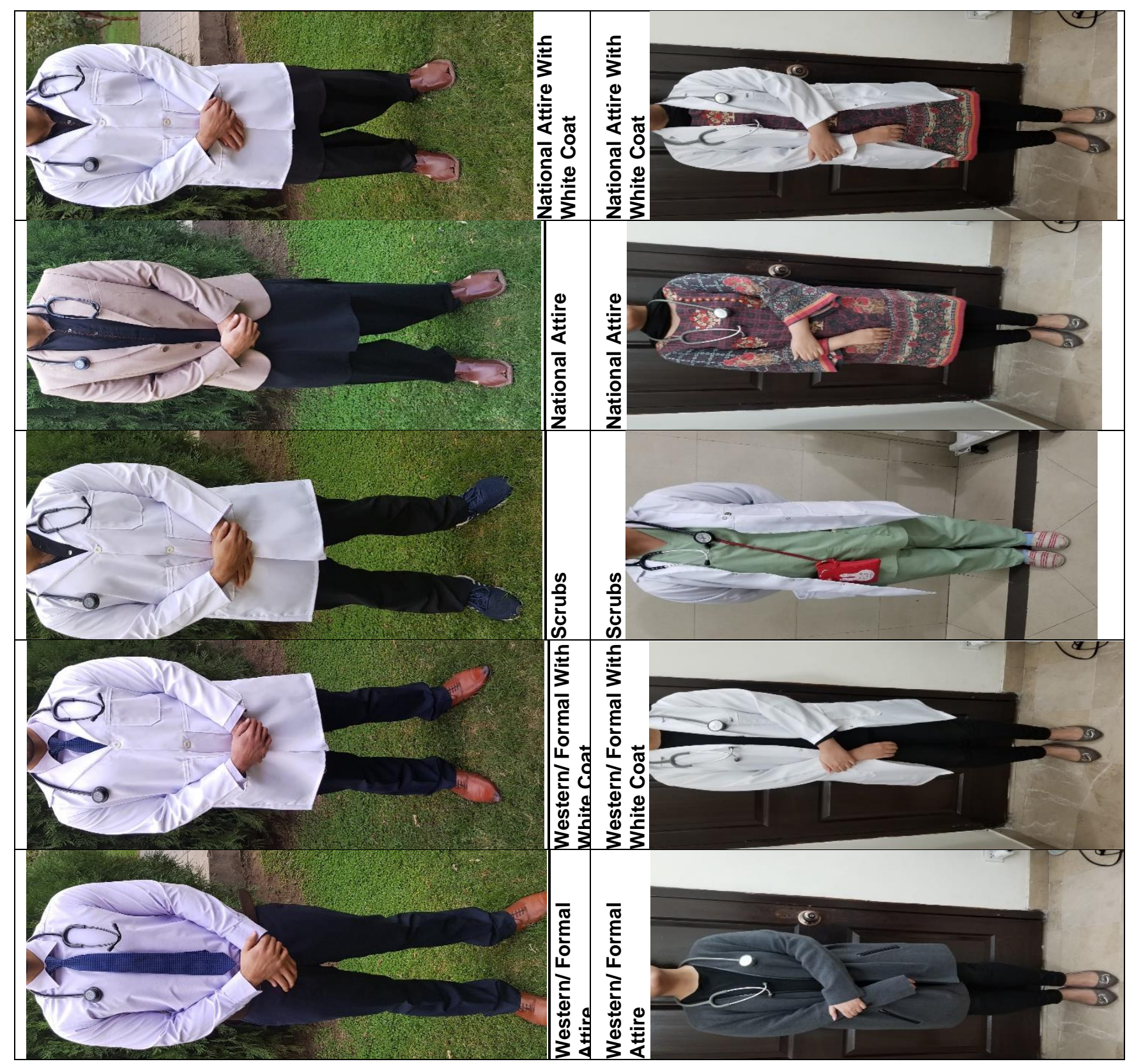

Figure 1

\section{RESULTS}

The sample size consisted of 96 patients of which $48(50 \%)$ were male and $48(50 \%)$ were female. The age of respondent included $13(13 \%)$ patients from 18-25 age group, 20 (20.8\%) from 26-34 age group, 32 (33.3\%) from $35-54$ age group, $22(22.7 \%)$ from 55-64 age group and 9 $(9.4 \%)$ from 65 or above. 39 patients $(40.6 \%)$ belong to rural area and $57(59.4 \%)$ belonged from urban area. As far as employment status is concerned $33(34.4 \%)$ were unemployed, $41(42.7 \%)$ were employed, $4(4.2 \%)$ were retired and $18(18.8 \%)$ fall into other category. Education status wise, $26(27.1 \%)$ were illiterate, $24(25 \%)$ had acquired education less than high school, $10(10.4 \%)$ had been to college and $3(3.1 \%)$ had graduated or above.
The patients' preferences were nearly identical for all outpatient, inpatient and emergency departments. For male physicians, formal/western attire with white coat was the most preferred with $53.1 \%$ of patients opting for it for outpatient (Fig.2), 54.2\% for inpatient (Fig.3) and $49.0 \%$ for emergency department (Fig.4). It was followed by formal/western attire at $17.7 \%$ for outpatient (Fig.2), $17.7 \%$ for inpatient (Fig.3) and 18.8\% (Fig.4) for emergency department. Casual attire was the least preferred attire across the board with $4.2 \%$ choosing it for outpatient (Fig.2), 3.2\% for inpatient (Fig.3) and $4.2 \%$ for emergency department (Fig.4). 


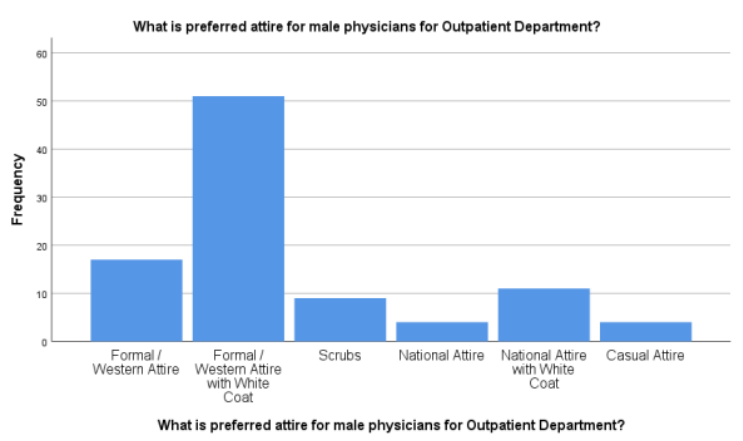

Figure 2:

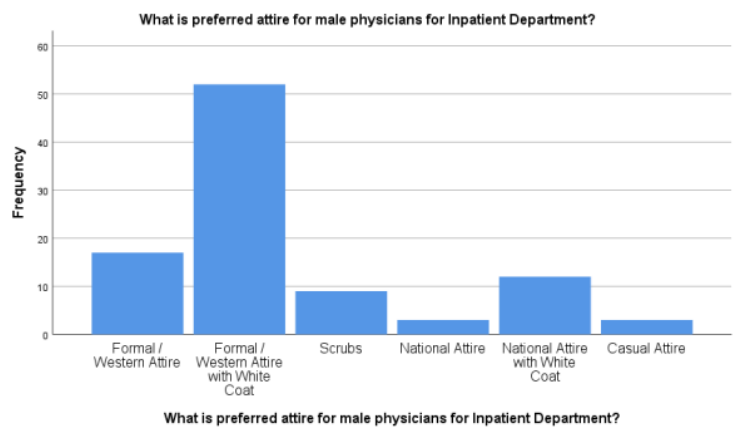

Figure 3

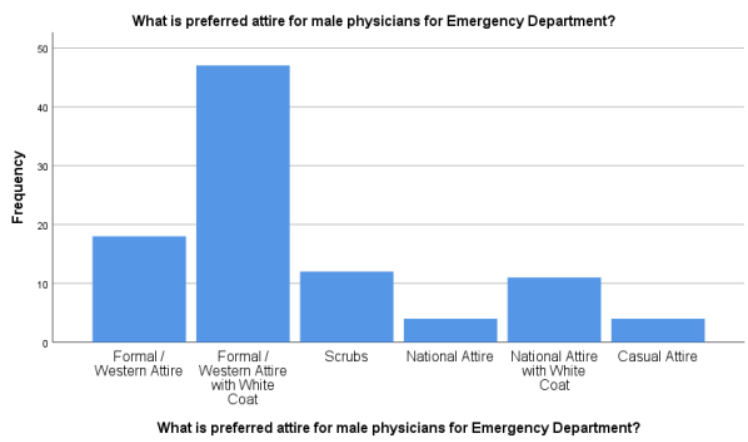

Figure 4

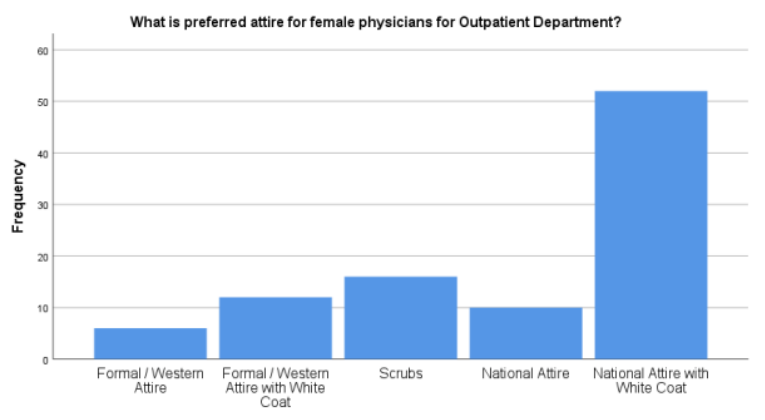

Figure 5

For female physicians, national attire with white coat was picked by the majority of the patients which included $54.2 \%$ for outpatient (Fig.5), 57.3\% for inpatient (Fig.6) and $58.0 \%$ for emergency department (Fig.7). It was followed by scrubs option which had approval rating of $16.7 \%$ in outpatient (Fig.5), 16.7\% in inpatient (Fig.6) and 21.9\% in emergency department (Fig.7). Casual attire was the least liked with $0 \%$ preference in both outpatient (Fig.5) and inpatient (Fig.6) and 1\% in emergency department (Fig.7).

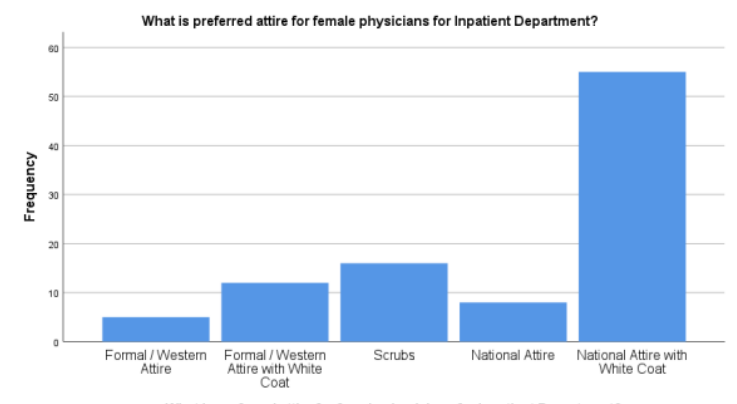

Figure 6

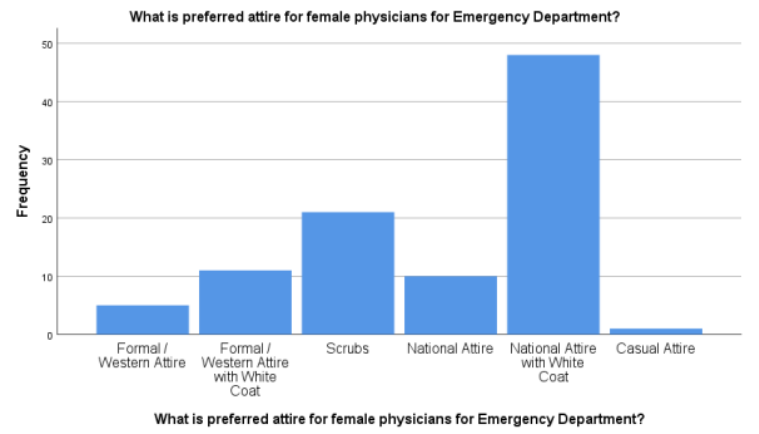

Figure 7

$78.1 \%$ of patients believed that doctor dress is important to them with only $2.1 \%$ patients disagreeing. $63.5 \%$ of patients felt that the doctor should wear his name tag. An overwhelming percentage of 84.4 of patients said that their doctor should wear a white coat (Tab.1).

Table 1

\begin{tabular}{|c|c|c|}
\hline & Frequency & Percentage \\
\hline \multicolumn{3}{|c|}{ My doctor dress is important to me } \\
\hline Strongly Disagree & 0 & 0 \\
\hline Disagree & 2 & 2.1 \\
\hline Neutral & 3 & 3.1 \\
\hline Agree & 16 & 16.7 \\
\hline Strongly Agree & 75 & 78.1 \\
\hline \multicolumn{3}{|c|}{ My doctor dresses influence how happy I am with the care I receive } \\
\hline Strongly Disagree & 0 & 0 \\
\hline Disagree & 2 & 2.1 \\
\hline Neutral & 6 & 6.3 \\
\hline Agree & 53 & 28.1 \\
\hline Strongly Agree & 35 & 63.5 \\
\hline \multicolumn{3}{|c|}{ My doctor should wear a name tag } \\
\hline Strongly Disagree & 1 & 1.0 \\
\hline Disagree & 1 & 1.0 \\
\hline Neutral & 6 & 6.3 \\
\hline Agree & 27 & 28.1 \\
\hline Strongly Agree & 61 & 63.5 \\
\hline \multicolumn{3}{|c|}{ My doctor's clothing is important to generate respect } \\
\hline Strongly Disagree & 2 & 2.1 \\
\hline Disagree & 8 & 8.3 \\
\hline Neutral & 12 & 12.5 \\
\hline Agree & 37 & 38.5 \\
\hline Strongly Agree & 37 & 38.5 \\
\hline
\end{tabular}




\begin{tabular}{|l|l|l|}
\hline Strongly Disagree & 4 & 4.2 \\
Disagree & 40 & 41.7 \\
Neutral & 16 & 16.7 \\
Agree & 20 & 20.8 \\
Strongly Agree & 16 & 16.7 \\
\hline The way my doctor dresses reflects his/her knowledge and \\
competence? & 2 & 2.1 \\
\hline Strongly Disagree & 16 & 16.7 \\
Disagree & 23 & 24.0 \\
Neutral & 25 & 26.0 \\
Agree & 30 & 31.3 \\
Strongly Agree & 1 & 1.0 \\
\hline My doctor's attire would affect my trust and confidence in him/her? \\
\hline Strongly Disagree & 1 & 1.0 \\
Disagree & 11 & 11.5 \\
Neutral & 32 & 33.3 \\
Agree & 51 & 53.1 \\
Strongly Agree & \multicolumn{2}{|}{} \\
\hline My doctor should wear a white coat & 0 & 0 \\
\hline Strongly Disagree & 1 & 1.0 \\
Disagree & 3 & 3.1 \\
Neutral & 11 \\
Agree & 81 & 11.5 \\
Strongly Agree & \multicolumn{2}{|l|}{} \\
\hline
\end{tabular}

The patients preferred that their doctors show good care of hygiene with regular laundering. Most of the patients preferred shorter hair length and trimmed nails for male physicians. Tattoos and ear/nose piercings were frowned upon by the patients for male physicians. Longer hair length in female physicians was acceptable by patients.

\section{DISCUSSION}

It has been showed via previous studies that there are conscious [13,14] and unconscious biases in patients regarding their physician's attire. So, it was not surprising to find out that patients have specific preferences as to what their doctor should wear. White coat is preferred by most of the patients for both their male and female provider (Tab.1) which is consonant with similar studies done regarding this $[15,16,17,18,19,20,21]$. There is a heterogeneous group of ever-changing preferences regarding this as studies in family practice setup in South Carolina found no predilection ${ }^{[22,23]}$, whereas white coats were preferred in internal medicine and surgical patients in South Carolina and Texas respectively [24,25]. As per Gooden et al [26], patients had a better rapport building with doctors who wore white coats. Similarly, Chae et al ${ }^{[27]}$ reported comparable findings of increased confidence building in patients due to white coats. White coats also aid spotting doctors in a bustling clinical environment in hospitals ${ }^{[26]}$.

Another facet for this white-coat wearing practice is that it has been demonstrated that bacteria and pathogens can be isolated from white coats, neckties and sleeves of medical professionals [28-36]. This study has led to "bare below the elbow" (BBE) policy in some countries. On the other hand, data suggests wearing a white coat leads to mere attentiveness to work [37]. This information has led to the phenomenon of "enclothed cognition" [38]. As a result, a doctor wearing white coat may be more particular about his hygiene $[39,40]$.

A study done by Ridd et al., ${ }^{[41]}$ shows that consultation experience is a fundamental pillar of doctorpatient interaction. The physician's attire as a modifiable variable, can help in enhancement of this relation. There was not much discrepancy among different age groups and sex regarding attire preferences. Therefore, recommendations cannot be made in future for single-sex wards. Patients preferred their doctors to wear daily laundered clothes which could also help in curbing spread of infection.

Western attire with white coat was mostly preferred for male physicians (Fig.2,3,4). One reason can be that it conveys authority and inspires more trust among patients. Casual dressing was least opted for as this ungroomed appearance can be linked with less competence by patients (Fig.2,3,4). National attire with white coat was preferred for female physicians by the vast majority of the participants (Fig.5,6,7). This can be explained by the religious inclination of the patients which translated to preferring conservative dressing for the female doctors.

The limitations of this study include just one hospital surveyed over brief period of time which could lead to bias. Second, patients, who were receiving care were asked to participate in this study which can lead to a possibility that these predispositions were more about current care rather than attire. Other dynamics of doctor-patient relationship were not studied which could have further helped in eliciting more accurate data ${ }^{[42]}$. Furthermore, Likert scale was used which ranges from strongly disagree to strongly agree. On one hand, it is a good tool but on the other it is restrictive in understanding patient's actual sentiments. Similarly, patients were shown pictures of physicians who were young and slender which can lead to bias in responses.

Further research work is warranted so that more facets can be studied. A large sample size should be used so there is minimum introduction of bias. Attire for specific specialties can also be investigated. Scrubs were not much preferred by patients which could be due to less awareness among patients of Pakistan which is a third world country. Education of patients and then re-assessing their predilections could yield different results. Alternative options including bare below elbows can be explored. Improved technologies namely antimicrobial fabrics is one another fascinating aspect to be assessed.

Long story short, clinical acumen remains unmatched in treating patients, but a doctors' apparel can go a long way in establishing trust and cementing a harmonious dynamics between a healthcare provider and the patient. In the ever-evolving field of medicine where treatment is being tailored towards each patient's individual needs, a provider's garb is an easily adjustable but a significant element to be considered in this matter. Implementation of such patient's preferred attires in clinical and emergency setting can ultimately reflect as more refined and upgraded healthcare services.

\section{CONCLUSION}

Patients prefer their healthcare provided to dress professionally with good grooming habits. A white coat along with name tag is favored by patients. Western attire with white coat is preferred for male doctors while national attire with white coat is fancied for female doctors by patients. This can help inculcate confidence in patients regarding their physician's proficiency, which could help in improving healthcare services in the long run. 
Acknowledgement: Special thanks to Dr. Amina Azhar, Dr. Hamna Sarwar and Dr. Haseeb Sheikh for modelling for photographs.

\section{Conflict of interest: None}

\section{REFERENCES}

1. Kurihara H, Maeno T, Maeno T. Importance of physicians' attire: factors influencing the impression it makes on patients, a crosssectional study. Asia Pac Fam Med 2014;13:2

2. Menahem S, Shvartzman P. Is or appearance important to our patients? Fam Pract 1998;15:391-7.

3. Rehman SU, Nietert PJ, Cope DW, Kilpatrick AO. What to wear today? Effect of doctor's attire on the trust and confidence of patients. Am J Med 2005;118:1279-86.

4. Gooden BR, Smith MJ, Tattersall SJ, Stockler MR. Hospitalised patients' views on doctors and white coats. Med J Aust 2001;175:219-22.

5. Harnett PR. Should doctors wear white coats? Med J Aust 2001;174:343-4.

6. Au S, Khandwala F, Stelfox HT. physician attire in the intensive care unit and patient family perceptions of physician professional characteristics. JAMA Intern Med 2013;173:465-7.

7. Lill MM, Wilkinson TJ. Judging a book by its cover: descriptive survey of patients' preferences for doctors' appearance and mode of address. Br Med J 2005;331:1542-7.

8. Gallagher J, Waldron Lynch F, Stack J, Barragry J. Dress and address: patient preferences regarding doctor's style of dress and patient interaction. Ir Med J 2008;101:211-3.

9. Gherardi G, Cameron J, West A, Crossley M. Are we dressed to impress? A descriptive survey assessing patients' preference of doctors' attire in the hospital setting. Clin Med 2009;9:519-24

10. Kurihara H, Maeno T, Maeno T. Importance of physicians' attire: factors influencing the impression it makes on patients, a crosssectional study. Asia Pac Fam Med 2014;13:2

11. Petrilli CM, Saint S, Jennings JJ, et al. Understanding patient preference for physician attire: a cross-sectional observational study of 10 academic medical centres in the USA. BMJ Open 2018;8:e021239. doi:10.1136/ bmjopen-2017-021239

12. Gul Farah, Savul Saba, labal Perwaiz Saima, et al. Patient preference for doctor attire: A cross-sectional study from Islamabad, Pakistan. Rawal Medical Journal:2019;44.4.

13. Rehman SU, Nietert PJ, Cope DW, et al. What to wear today? Effect of doctor's attire on the trust and confidence of patients. Am J Med 2005;118:1279-86.

14. Beach MC, Fitzgerald A, Saha S. White coat hype: branding physicians with professional attire. JAMA Intern Med 2013;173:467-8

15. McKinstry B,Wang J. Putting on the style: what patients think of the way their doctor dresses. Br J Gen Pract 1991;41:275-8.

16. Douse J, Derrett-Smith E, Dheda K, Dilworth JP. Should doctors wear white coats? Postgrad Med J 2004;80:284-6.

17. Gooden BR, Smith MJ, Tattersall SJ, Stockler MR. Hospitalised patients' views on doctors and white coats.Med J Aust 2001;175:219-22.

18. Harnett PR. Should doctors wear white coats? Med J Aust 2001;174:343-4.

19. Rehman SU, Nietert PJ, Cope DW, Kilpatrick AO.What to wear today? Effect of doctor's attire on the trust and confidence of patients. Am J Med 2005;118:1279-86.

20. Manahem S, Shvartzman P. Is our appearance important to our patients? Fam Pract 1998;15:391-7.

21. Ikusaka M, Kamegai M, Sunaga $T$ et al. Patients' attitudes towards consultations by a physician without a white coat in Japan. Intern Med 1999;38:533-6.
22. Cha A, Hecht BR, Nelson K, Hopkins MP. Resident physician attire: does it make a difference to our patients? Am J Obstet Gynecol. 2004 May;190(5):1484-1488

23. Hueston WJ, Carek SM. Patients' preference for physician attire: a survey of patients in family medicine training practices. Fam Med. 2011 Oct;43(9):643-647

24. Rehman SU, Nietert PJ, Cope DW, Kilpatrick AO. What to wear today? Effect of doctor's attire on the trust and confidence of patients. Am J Med. 2005 Nov;118(11):1279-1286.

25. Edwards RD, Saladyga AT, Schriver JP, Davis KG. Patient attitudes to surgeons' attire in an outpatient clinic setting: substance over style. Am J Surg. 2012; Nov(5):663-665. Epub 2010 Jun 29

26. Gooden BR, Smith MJ, Tattersall SJ, Stockler MR. Hospitalised patients' views on doctors and white coats. Med J Aust. 2001 Aug 20;175(4):219-222.

27. Cha A, Hecht BR, Nelson K, Hopkins MP. Resident physician attire: does it make a difference to our patients? Am J Obstet Gynecol. 2004 May;190(5):1484-1488.

28. Bearman G, Bryant K, Leekha S, et al. Healthcare personnel attire in non-operating-room settings. Infect Control Hosp Epidemiol 2014;35:107-21.

29. Ditchburn I. Should doctors wear ties? J Hosp Infect 2006;63:227-8.

30. Munoz-Price LS, Arheart KL, Mills JP, et al. Associations between bacterial contamination of health care workers' hands and contamination of white coats and scrubs. Am J Infect Control 2012;40:e245-8.

31. Gaspard P, Eschbach E, Gunther D, et al. Methicillin-resistant Staphylococcus aureus contamination of healthcare workers' uniforms in long-term care facilities. J Hosp Infect 2009;71:1705.

32. Loh $\mathrm{W}, \mathrm{Ng} \mathrm{VV}$, Holton J. Bacterial flora on the white coats of medical students. J Hosp Infect 2000;45:65-8.

33. Lopez PJ, Ron O, Parthasarathy P, et al. Bacterial counts from hospital doctors' ties are higher than those from shirts. Am $\mathrm{J}$ Infect Control 2009;37:79-80.

34. Perry C, Marshall R, Jones E. Bacterial contamination of uniforms. J Hosp Infect 2001;48:238-41.

35. Bearman GM, Rosato A, Elam K, et al. A crossover trial of antimicrobial scrubs to reduce methicillin-resistant Staphylococcus aureus burden on healthcare worker apparel. Infect Control Hosp Epidemiol 2012;33:268-75.

36. Treakle AM, Thom KA, Furuno JP, et al. Bacterial contamination of health care workers' white coats. Am J Infect Control 2009;37:101-5.

37. Hutson MRT. Dress for Success: How Clothes Influence Our Performance. Scientific American, a division of Nature America, Inc, 2016.

38. Adam H, Galinsky AD. Enclothed cognition. J Exp Soc Psychol 2012;48:918-25.

39. Kalb C. How a team of doctors at one hospital boosted hand washing, cut infections and created a culture of safety: Yahoo News. 2014 https://www. yahoo. com/ news/ clean- handsvanderbilt- s- handwashing- initiative- 172312795. html (accessed June 12, 2017).

40. Pittet D, Simon A, Hugonnet S, et al. Hand hygiene among physicians: performance, beliefs, and perceptions. Ann Intern Med 2004;141:1-8.

41. Ridd M, Shaw A, Lewis G, Salisbury C. The patient-doctor relationship: a synthesis of the qualitative literature on patients' perspectives. Br J Gen Pract. 2009 Apr:59(561):e116-e133.

42. Petrilli CM, Mack M, Petrilli JJ, et al. Understanding the role of physician attire on patient perceptions: a systematic review of the literature--targeting attire to improve likelihood of rapport (TAILOR) investigators. BMJ Open 2015;5:e006578. 